\title{
Retratos de fascismos brasileiros: a relação de Teocrasília e a nova ordem com o bolsonarismo
}

\section{Sergio Schargel ${ }^{1}$}

Resumo: A distopia é uma das formas mais políticas que a literatura pode assumir, já que absorve traços de políticas do real para distorcê-lo sob a forma de um pesadelo. Nesse escopo, é sintomático que as obras Teocrasília, publicada em 2018, e A nova ordem, de 2019, sejam lançadas no período de ascensão de um movimento "ur-fascista" no Brasil, para usar o conceito criado por Umberto Eco. Ambas absorvem fragmentos do bolsonarismo e, no processo de falsificação do real, criam um real literário em que um ur-fascismo brasileiro se tornou totalitário. Este trabalho colocará em diálogo a teoria política sobre ur-fascismo com os dois objetos, a fim de entender como traços desse movimento político são apreendidos pela ficção. Dessa forma, contribuirá para o estado da arte ao permitir compreender o urfascismo em diversas de suas potencialidades, bem como as formas com que a literatura política recria a teoria política.

Palavras-chave: Teoria política. Distopia. Ur-fascismo.

m paralelo com a realidade, a ficção também tratou de dar diversas roupagens e imagens ao fascismo. $O$ subgênero da distopia, ou utopia negativa, é certamente responsável por grande parte dessas adaptações. É tarefa árdua falar de fascismo ou, ainda mais, distopia literária, sem citar, ao menos de passagem, 1984, de George Orwell. Orwell não foi o primeiro autor de distopias e, muito menos, o primeiro a escrever sobre uma sociedade totalitária recheada de características fascistas; mas certamente foi um dos mais influentes. Tão influente que, mais de meio século após ser escrito, 1984 voltou à lista de mais vendidos (MATOS, 2019, n. p.), interesse ressuscitado pela ascensão mundial de governos autoritários reais. Da mesma forma, obras como Nós, de Ievguêni Zamiátin, e Laranja

1 Doutorando em Comunicação pela UERJ, doutorando em Ciência Política pela UFF. Mestre em Letras pela PUC-Rio, mestrando em Ciência Política pela UNIRIO. 
mecânica, de Anthony Burgess, foram reeditadas nos últimos anos, para mencionar apenas algumas.

O número de distopias cresceu em popularidade nas últimas décadas (LEPORE, 2017, n. p.), imaginando os mais diferentes futuros aterradores possíveis. Grande parte delas intersecciona-se ao mostrar, nesses futuros, governos e sistemas autoritários, totalitários, fascistas, populistas, ou qualquer outro rótulo possível. Ainda que existam diversas distopias anteriores a essa época, a década de 1940 entrou para o imaginário popular de tal forma que a ficção se apropriou da ideia e imaginou diversos formatos em que a barbárie poderia repetir-se. E não é por coincidência: da mesma forma que o crescimento do subgênero da distopia, no início do século XX, foi influenciado diretamente pelas várias catástrofes da primeira metade do século (HUXLEY, 2000, p. 15), formando uma geração de escritores que eram capazes de ver na destruição humana uma estética, parafraseando Benjamin (1994, p. 196), a recessão democrática contemporânea faz com que pululem novas obras sobre os "ismos". A política no real influencia na política da ficção, logo 1984 não voltou a ser best-seller sem motivo (MATOS, 2019, n. p.).

Assim, mesmo com necessárias comparações entre políticas da realidade, entre fascismos que existem e existiriam e, tanto mais, entre as interseções entre política e literatura, a intenção aqui será trabalhar com fascismos possíveis, com aparições de fascismos na literatura, isto é, com a forma com que a literatura brasileira contemporânea, por meio das duas obras que são objetos de análise deste trabalho, vem apresentando versões desses fascismos. Apreendendo uma estética da destruição nas duas obras escolhidas, pretende-se analisar, à luz das principais características apontadas, o formato que essa metodologia política adquire em cada uma. Com a ciência de que os fascismos da literatura não podem ser uma imitação absoluta dos fascismos reais, ainda assim essas interpretações literárias são úteis para assimilar o que o fascismo pode ser. De acordo com 
Cass Sunstein, em Can it happen here?, uma coletânea de artigos e ensaios que discutem a atual fragilização democrática global:

Uma história de ficção especulativa pode nos dizer algo importante e até profundo sobre nós mesmos. Ela se apodera de alguma característica de nosso caráter nacional - pequeno ou grande, oculto ou aberto - ou de alguma inclinação que algumas pessoas têm, e mostra o que poderia ter acontecido se essa característica ou tendência tivesse de alguma forma florescido. O livro de Roth, Complô contra a América, é uma obra-prima dessa corrente. A ficção especulativa nos avisa: dentro de cada coração humano, há um fascista esperando para sair. (SUNSTEIN, 2018, p. IX, tradução nossa).

\section{Entendendo um conceito polissêmico}

Em Can it happenhere?, Jack M. Balkin argumenta que o fascismo não poderia acontecer atualmente nos Estados Unidos, porque o "governo americano é muito largo e descentralizado" (SUNSTEIN, 2018, p. 36, tradução nossa). Longe de ser inédito, o mesmo argumento pode ser visto repetidas vezes, utilizado principalmente por pesquisadores que preferem trabalhar com conceitos como "populismo", como Yascha Mounk (2018). David Runciman (2018, p. 8), por exemplo, sugere que o fascismo não pode reaparecer em 2020 porque "nossas sociedades são diferentes demais - prósperas demais, idosas demais, interligadas demais -, e trazemos profundamente arraigado um conhecimento histórico coletivo do que deu errado àquela altura." É no mínimo ingênuo acreditar que um fascismo não pode surgir em uma democracia consolidada e até outrora estável; isso sem expandir a discussão à leviandade de acreditar que a sociedade absorveu as lições do século XX, em um momento em que manifestações neonazistas e antissemitas crescem em algumas partes do mundo como na própria Alemanha (ANTISSEMITISMO, 2019, n. p.). No entanto, o fascismo, em 
mais uma de suas dissonâncias em relação ao autoritarismo, atua justamente por lentas etapas, passo por passo, depenando uma galinha pena por pena, como dizia Mussolini (ALBRIGHT, 2018, p. 124). Ele não surge de uma ruptura, mas de um processo gradual. Na verdade, se certamente Estados como Estados Unidos e Brasil não se tornariam fascistas da noite para o dia, nada impede que isso aconteça após um longo período de sucessivos esvaziamentos democráticos. Um exemplo contemporâneo pode ser visto em Viktor Orbán, que, há pelo menos uma década, vem cerceando o espaço cívico na Hungria, tornando a nação progressivamente mais autoritária e concentrando cada vez mais poder. Desde a eleição de líderes antidemocráticos, tanto o Brasil quanto os Estados Unidos decaíram em alguns índices de democracia, como o da Freedom House (NEW REPORT, 2020) e o da The Economist (GLOBAL, 2020, n. p.), evidenciando que há, de fato, um processo de fragilização democrática que pode ou não evoluir para uma fascistização do Estado.

Com efeito, conforme mostra Evguiéni Pachukanis (2020, p. 52), desde o início, o fascismo italiano e o alemão foram apontados por teóricos liberais como equivalentes ao bolchevismo. De fato, o fascismo surge paradoxalmente como um movimento antiliberal e anticomunista, uma tentativa de terceira via personificada por um ex-socialista, com uma retórica populista de retomar o poder das mãos de uma elite corrupta e concedê-lo de volta à nação; ou, em outras palavras, tornar a nação grande novamente. O próprio fascismo se dizia "nem de esquerda nem de direita", afirmando que teria "transcendido essas divisões arcaicas e unido a nação" (PAXTON, 2007, p. 28). Todavia, conforme os anos se passaram, a retórica anticapitalista foi arrefecendo, ao passo que a perseguição a comunistas se manteve constante, e o movimento foi gradualmente guinando cada vez mais à direita (FELICE, 1976, p. 72).

No outro lado do espectro, teóricos marxistas, desde 1920, tratam o fascismo e o Nazismo como o último espasmo de um capitalismo 
moribundo, um contra-ataque de uma democracia liberal prestes a morrer (FELICE, 1976, p. 74). A posição marxista sobre o fascismo, adotada já no Terceiro Congresso da Internacional Comunista e reforçada por pensadores como Toglitatti, foi, em parte, inclusive, responsável por relativa apatia da esquerda em relação ao fascismo, adiando uma reação por considerar que fascismo e democracia liberal eram a mesma coisa. A Internacional publicou uma resolução, ainda em 1923, que reforçava que "o fascismo é um fenômeno de decadência característico do nosso tempo e expressão da progressiva dissolução da economia capitalista e da corrupção do Estado burguês" (FELICE, 1976, p. 75). Não ajuda que os comunistas classificassem a social-democracia como social-fascismo (BRAY, 2019, p. 74-75), dando início a um longo processo histórico de banalização do conceito de fascismo. Tanto a análise liberal quanto a análise marxista são insuficientes para compreender no âmago um movimento contraditório e polissêmico que transcende a política e atinge esferas até mesmo psicológicas, como Adorno (1964) e seus companheiros de pesquisa evidenciaram em Authoritarian personality.

Umberto Eco (2018), entendendo essas diferenças entre as reconstruções do fascismo, criou o conceito de "ur-fascismo", ou fascismo eterno, isto é, um fascismo que se atualiza conforme suas aparições, ao mesmo tempo em que mantém algumas características em destaque. Enquanto existir sociedade de massas, seu bacilo estará sempre presente (SCHARGEL, 2020). Pode estar adormecido, entorpecido, mas espera apenas uma oportunidade para retornar. Nesses retornos, manifesta características distintas, dissimuladas, escondidas, mas mantém alguns dos velhos hábitos que o permitem ainda ser identificado. Essa é a principal razão pela qual o termo se torna tão elástico: não há apenas um fascismo. Mesmo o Nazismo, que não deixava de ser por si só um fascismo elevado exponencialmente, era distinto do fascismo italiano. Considerando outros movimentos como fascistas, essas diferenças se tornam ainda mais 
acentuadas (ECO, 2018, p. 42-43).

Esse aspecto, inclusive, seria posteriormente retomado por outros autores que se dedicaram ao estudo do fascismo, como Madeleine Albright e Jason Stanley, que defendem que o fascismo "deva ser visto menos como ideologia política e mais como forma de se tomar e controlar o poder" (ALBRIGHT, 2018, p. 17). Isso é algo que Foucault já havia, de certa forma, percebido, ao afirmar que "as massas, no momento do fascismo desejam que alguns exerçam o poder, alguns que, no entanto, não se confundem com elas, visto que o poder se exercerá sobre elas" (FOUCAULT, 1979, p. 77). Isto é, o Fascismo italiano e os demais fascismos europeus da mesma época, e, posteriormente, a sua versão ampliada, o que se entende aqui por "ur-fascismo", caracterizam-se essencialmente pela relação direta com o poder, que, supostamente usurpado, seria resgatado e trazido de volta à nação e à seita escolhida. São movimentos cuja centralidade, ainda mais do que a ideia de nação, consiste no desejo de atingir, controlar e manter o poder e, para tanto, constituem-se como um método com características que mesclam estratégias populistas, nacionalistas, autoritárias e reacionárias.

Em parte devido à fragilidade de sua ideologia - o poder veio primeiro, a ideologia depois -, torna-se difícil entender o fascismo como um sistema com ideologias claras e definidas. Mesmo o Nazismo, por si próprio uma ramificação do fascismo, possuía o Mein kampf como manifesto de uma doutrina que antecede uma movimentação política de fato, ao menos se for ignorado o desorganizado putsch da cervejaria de Hitler. O fascismo, ao contrário, surge primeiro para ser pensado depois. Mussolini apenas nomeou um movimento que já existia. $\mathrm{O}$ fascismo italiano rotulou um movimento internacional inevitável que existiria com qualquer nome que lhe fosse dado.

É preciso ressaltar que não necessariamente uma metodologia fascista conduz a um Estado fascista (STANLEY, 2018, p. 14). Diversos fatores, incluindo a receptividade e o caldo cultural da população, a 
estabilidade democrática e a força da oposição e das instituições, podem impulsionar ou frear um processo de fascistização. Em outras palavras, há inúmeras variáveis que podem influenciar na ascensão do fascismo, em especial após a sua tomada do poder.

\section{Sobre ur-fascismos na literatura}

Após as eleições de 2018, dezenas de novos livros surgiram no país pensando seu resultado, tanto no plano teórico quanto no ficcional. Podese pensar em livros como Teocrasília, de Dênis Mello, Essa gente, de Chico Buarque e A nova ordem, de Bernardo Kucinski, lançados entre em 2018 e 2019, são exemplos de como algumas ficções contemporâneas retratam aspectos do bolsonarismo ao mesmo em que se lhe opõe.

É nesse contexto fértil que Bernardo Kucinski, ex-professor de Jornalismo da USP, publicou seu terceiro romance, A nova ordem. Seu primeiro romance, $K$., viajou nas fronteiras entre a realidade e a ficção, ao abordar as tentativas desesperadas de seu pai de encontrar o corpo de sua filha, sua irmã assassinada durante a ditadura militar. $\mathrm{O}$ próprio autor foi preso e forçado ao exílio durante o mesmo período. O romance seguinte, Os visitantes, mais uma vez colocando a realidade em diálogo com a ficção, imagina uma série de visitantes chegando à casa de Kucinski para reclamar de seu último livro, principalmente amigos e conhecidos de sua irmã, acusando-o de modificar o real em favor do literário. Em A nova ordem, entretanto, Kucinski distancia-se de seus trabalhos anteriores. A novela imagina um Brasil distópico e totalitário, com traços identificáveis do bolsonarismo, incluindo um personagem secundário que compartilha o segundo nome de Bolsonaro e sua posição no exército, Capitão Messias. A lógica dessa distopia, porém, é semelhante à nossa. Não existem criaturas fantásticas, robôs assassinos, televisores que assistem às pessoas vinte e quatro horas por dia ou drogas que mudam a percepção humana. O 
universo criado por Kucinski é crível, verossímil, uma mistura da ditadura militar brasileira com o Nazismo, uma ideia do que poderia ser um totalitarismo brasileiro.

O livro constitui-se de pequenos contos em formato de romance. Cada capítulo contém uma história independente, lidando com diferentes personagens e sua reação a esse contexto. Entretanto, a história principal é sobre a tentativa obcecada de um dos principais governantes, um psicanalista, de criar um chip que possibilite o controle mental - o que, na prática, facilitaria o extermínio da população indesejada. Esse é o único detalhe que escapa ao que se poderia chamar de mimese perfeita, uma pequena dose de fantasia sobrenatural que intensifica a representação política. No entanto, nada mais é do que a transposição para a ficção do que Hannah Arendt chama a atenção em Origens do totalitarismo. Como ela mostra, o totalitarismo é obcecado com a ideia absurda de controle da mente: "Na verdade o raciocínio simplório que existe por trás do uso desse mecanismo só pode ser explicado pelo desejo irracional de que, afinal de contas, seja possível a leitura da mente" (ARENDT, 1978, p. 195). Na obra de Kucinski, o sonho totalitário do controle mental é posto em prática literalmente: "Obtido um chip eficaz, seria possível fazer das novas gerações uma população dócil, passiva, que aceitará tudo o que lhes for dado e fará o que lhes for ordenado sem contestar" (KUCINSKI, 2019, p. 150). O fantástico, em A nova ordem, portanto, ilumina a teoria política e contribui para a crítica não apenas a um fascismo da ficção, mas ao fascismo da realidade.

A nova ordem transforma a violência política e a repulsa dela decorrente em humor. Embora apresente um enredo extremamente violento, é permeado por uma comicidade sarcástica. Por exemplo, em dado momento do livro, após revelar planos de genocídio, extermínio racial, deportações em massa, esterilização humana, entre outras violências, o General Lindoso Fagundes afirma que, por permitir que algumas das 
crianças feitas órfãs nessas operações sejam enviadas para orfanatos católicos, eles, afinal, não são desumanos (KUCINSKI, 2019, p. 129). O riso de Kucinski é baseado no absurdo: o totalitarismo ur-fascista é tão inacreditável por si só, que suas contradições, mesmo diante do horror, acabam tomadas pela ironia.

Longe de ser totalitário, mas ainda em um regime que se utilizou de medidas de poder ur-fascistas, o na época Ministro da Casa Civil brasileiro, Onyx Lorenzoni, realizou um expurgo em massa assim que tomou posse, demitindo todos os funcionários que tivessem ideologias contrárias à da situação. Lorenzoni, porém, demitiu tantos trabalhadores que, ao querer demitir mais, chegou ao ponto de não conseguir, porque havia demitido quem demitia (APÓS 'DESPETIZAÇÃO', 2019, n. p.). Conta Sérgio Porto uma anedota de que, na Ditadura, censores enviados pelo DOI-CODI invadiram um teatro com a intenção de prender o subversivo autor de uma peça, Sófocles (VIANNA, 2006). Longe de serem casos isolados, essas anedotas mostram a ironia que se faz presente em movimentos antidemocráticos, sejam eles de caráter autoritário, ur-fascista ou totalitário. $\mathrm{O}$ absurdo gerado pela tentativa de controle social acaba por gerar um humor mórbido baseado na obscuridade e megalomania.

Outro ponto importante de A nova ordem é o conspiracionismo paranoico. No livro, qualquer um que questione, mesmo que minimamente, a Nova Ordem é classificado como "utopista". Nisto consiste a ironia de Kucinski: os utopistas não são grandes revolucionários ou rebeldes violentos, mas cidadãos comuns. O nome do "bode expiatório" não poderia ser mais apropriado: em uma terra totalitária e planificada, o pensamento é utópico por si só. Onde só há espaço para o total, o menor desvio somente pode ser tomado como utópico.

Para lidar com a ameaça imaginária, a alta cúpula do poder da Nova Ordem utiliza tecnologias de vigilância sobre redes sociais como WhatsApp, identificando supostos subversivos com o auxílio de palavras- 
chave (KUCINSKI, 2019, p. 64-65). Longe do processo idealizado que as redes sociais assumiram em movimentos como a Primavera Árabe, na qual eram tomadas como ferramenta de mudança de paradigma, em $A$ nova ordem, elas contribuem para o controle totalitário, desdobrando-se e tornando-se ferramenta de manipulação. Assim como a teletela em 1984, o WhatsApp em A nova ordem se torna Argos, o olho que tudo vê, tornando possível ao regime, em primeiro momento, identificar e esmagar qualquer mínimo pensamento crítico ou, para usar os termos do livro, utópico.

Ao passo que os utopistas de classes médias ou baixas são desumanizados e tratados como criminosos comuns, os de famílias tradicionais são tratados apenas como crianças mimadas e rebeldes, mas recuperáveis. Em mais uma característica verossímil do que seria um totalitarismo brasileiro, o Estado em $A$ nova ordem é essencialmente paternalista - para os que estão dentro da cúpula do poder, claro. Assim como no patrimonialismo do Estado brasileiro em nossa realidade, na realidade da ficção o Estado "tem significação análoga à da autoridade paterna, em especial, porque estamos falando de famílias patriarcais" (KUCINSKI, 2019, p. 68). O Estado patrimonialista, como o grande pai, deve castigar os seus filhos rebeldes, mas sempre com a ciência de que são seus filhos e, portanto, a eles não cabe a eliminação. A ciência é deturpada e, dessa vez, a psicanálise é utilizada como justificativa:

"A raiz do delito político do utopista de família rica é edipiana; o poder do pai, que ele substitui pelo poder do Estado, precisa ser destruído pela ação revolucionária, para que a pátria, que ele identifica com a mãe, seja possuída." (KUCINSKI, 2019, p. 68).

É mais fácil imaginar uma distopia quanto mais mimética ela for. No caso brasileiro, em que política e religião são sinônimos e o Estado laico é uma maquiagem, não é difícil imaginar uma involução da democracia para uma teocracia de fato. A bancada evangélica na Câmara é maior 
do que qualquer partido, contendo 20\% do Congresso (VEJA, 2020). Foi uma das maiores forças por trás da eleição de Bolsonaro em 2018, que, embora católico, é bastante simpático ao protestantismo. De fato, o fundamentalismo religioso, como sugere Luís Felipe Miguel (GALLEGO, 2018, p. 14), é um dos três principais eixos da extrema-direita brasileira, junto do libertarianismo e da histeria do perigo vermelho.

Nesse contexto, o artista Dênis Mello lançou a história em quadrinhos Teocrasília, uma distopia teocrática localizada em um Brasil de um futuro próximo. Na obra, as igrejas evangélicas assumiram o poder e transformaram o país em uma nação "temente a Deus", isto é, autoritária e sem espaço para qualquer tolerância religiosa. Teocrasília prevê uma teocracia em que não há mais espaço para a ciência. Nesse universo, as bolsas de ciência e tecnologia foram cortadas e as pós-graduações completamente extintas (MELLO, 2018, p. 45). Em época de "contingenciamento" da educação e cortes quase mensais nas bolsas de pesquisa, de crescimento do pentecostalismo e ur-fascismo, este cenário pode não ser tão improvável.

A história segue o tradicional modelo da jornada de herói, descrita por Joseph Campbell (2013). O protagonista precisa passar por uma série de provações consecutivas para tornar-se o herói e seguir o destino que estava guardado para si. Só quando perde sua noiva grávida e sua utopia, na destruição do santuário promovido pelos Templários, é que efetivamente se embrenha na resistência e volta a lutar contra o regime de forma aberta. É preciso a motivação da perda, portanto, para que o personagem se transforme em herói.

Um dos aspectos mais interessantes em Teocrasília é que se trata não apenas de uma distopia, mas também de uma utopia. Durante parte do livro, grupos contra o regime, em vez de lutar contra ele, estabelecem uma comuna utópica voltada para a subsistência. Por certo, embora a utopia de uma comunidade paralela seja esmagada, o seu processo de nascimento e morte é o que faz com que os personagens comecem a lutar contra o 
regime. É necessária a morte da utopia espacial, para que passem a buscar uma utopia temporal, pois resistir de forma direta a um regime totalitário, que controla as pessoas por meio do puro terror, é, por si própria, uma forma de utopia. Somente o desejo da utopia, da tentativa de criar um futuro ideal, é capaz de motivar um grupo a resistir e se debater de todas as formas possíveis.

Teocrasília, no mesmo estilo de 1984, oferece uma esperança ao leitor, o retiro utópico socialista em que uma pequena comunidade sobrevive sob os ideais do humanismo, onde há liberdade de pensamento, religião e arte. Entretanto, assim como 1984, essa esperança é esmagada não muito depois. Ao contrário de 1984, essa destruição não é absoluta: o protagonista ainda permanece vivo. A história não termina no volume de lançamento, já que permanece em aberto para as cinco continuações que o autor pretende desenvolver (SCHARGEL; UCHOA, 2020).

Com a ciência de que a ficção dobra o real, criando, no processo, seu próprio real, e na impossibilidade de apreender o nível de impacto da política do real na política da ficção, ainda assim é seguro afirmar que os desmontes democráticos impactam diretamente na ficção distópica. Não é algo novo: a influência da política na ficção ocorre desde a criação das primeiras manifestações desse subgênero da ficção científica, como Nós, de Zamiatin, ou Admirável mundo novo, de Huxley. O possível futuro impossível, a ideia de que o presente caminha à destruição, é a força motriz por trás da distopia, assim como a divinização do ideal é o que está por trás das utopias. A distopia, apesar de se passar no futuro, é consequência do presente. Entretanto, tanto a utopia quanto a distopia imprimem um descontentamento com a realidade, um desejo de mudá-la. A desilusão com o presente cria o futuro esvaziado ou idealizado.

É significativo, portanto, que ficções brasileiras que lidam com traços ur-fascistas, como Teocrasília e $A$ nova ordem, tragam o antiintelectualismo como força motriz de seus respectivos autoritarismos. Se 
em Teocrasília teatros e cinemas foram fechados, alguns deles inclusive apropriados e transformados em abrigos para festas clandestinas, em $A$ nova ordem eles foram apropriados e tornaram-se templos evangélicos (KUCINSKI, 2019, p. 110). Em ambos, a cultura, a arte, a ciência e a tecnologia são marginalizadas pelos respectivos regimes, não apenas tomados por supérfluos, mas, tanto mais, classificados como doutrinação ideológica comunista. Logo nas primeiras páginas do livro de Kucinski, acadêmicos são massacrados na Operação Cátedra.

Em A nova ordem, concretizam-se as ameaças que o setor artísticocultural brasileiro vem sofrendo há muito tempo, mas intensificadas após 2018. Se na realidade brasileira a Lei Rouanet não foi, ao contrário da ficção de Kucinski (2019, p. 110), extinta em absoluto, ela foi modificada em sua essência. A Ancine em Kucinski também é extinta, mas, no Brasil de 2020, ela, assim como a Secretaria Especial de Cultura, torna-se plataforma para uma "guerra cultural", conforme Roberto Alvim prometeu, disposta a premiar "artistas nacionalistas e conservadores" e a censurar "obras ideológicas" apenas quando a ideologia é contrária à ideologia do censor. O mesmo Roberto Alvim, antes de se travestir de Goebbels - no mínimo indicativo de aproximação ideológica com o ur-fascismo -, afirmou que pretendia criar um "exército de artistas espiritualmente comprometidos com nosso presidente e seus ideais" (BOGHOSSIAN, 2019, n. p.). Em $A$ nova ordem, o édito que extingue a Ancine e a Lei Rouanet afirma que “ constatou-se que incentivos fiscais à produção artística e cultural vinham sendo distribuídos a aristas que se opunham à Nova Ordem ou cujas obras afrontavam a Família e os Valores Morais da Nova Ordem, inclusive obras pornográficas” (KUCINSKI, 2019, p. 110). Em 2019, o Ministro da Cidadania do governo Bolsonaro afirmou que " $80 \%$ dos filmes brasileiros são feitos de doutrinação política", "os filmes brasileiros não podem ser só pornográficos" e "Obra de arte é obra de arte. Se for arte e não for só pornografia, vai ser respeitado" (TRINDADE, 2019). Em sua apreensão do 
real brasileiro para dobrá-lo na criação de um novo real, Kucinski intensifica ao ficcionalizar, por conseguinte, discursos e movimentos perceptíveis na política contemporânea brasileira.

Importante notar como Kucinski, não por acaso, coloca tanto família quanto valores morais em letras maiúsculas: como um movimento reacionário, o ur-fascismo adota instituições basilares do poder hegemônico e as eleva a um patamar divino, apenas rivalizados pelo Messias. Tanto a política da ficção quanto a política do real se entrelaçam no que tange ao discurso anti-intelectual, e em ambas a arte crítica é uma célula cancerígena a ser extirpada, uma afronta e um perigo ao diamante do poder. A Nova Ordem também cria o seu próprio Index Prohibitorum, proibindo a circulação de qualquer obra que o regime julgue como crítica ou que possa suscitar um pensamento crítico (KUCINSKI, 2019, p. 110).

Além da arte, também não há espaço para a ciência e tecnologia. A pesquisa é extinta, com o fim de instituições como $\mathrm{CNPq}$ e a Capes (KUCINSKI, 2019, p. 89). A pesquisa, com exceção da agropecuária e de áreas úteis à manutenção do poder, é considerada desperdício de dinheiro. De forma semelhante, em Teocrasília, as instituições de pesquisa também são aniquiladas pelo mesmo motivo. Ambos os autores imaginaram realidades em que os constantes ataques à ciência e tecnologia foram levados às últimas consequências, quando a mesma justificativa é utilizada para cortes de verbas em programas, em particular na área de humanidades. Como autores de distopias, cujas ideologias são opostas ao bolsonarismo, tanto Kucinski quanto Dênis Mello intensificam em suas respectivas ficções os atos negacionistas do ur-fascismo e levam-nos à última consequência.

O autor de Teocrasília, Dênis Mello, define seu livro e sua arte, em geral, como uma "arte antifa". Em evidente simbiose com a popularização de movimentos antifascistas em todo o mundo, como inevitável resposta de setores progressistas e democráticos ao crescimento do próprio urfascismo em si, o autor deixa claro que sua arte é, sim, militante, e que 
não há nenhum problema nisso, rechaçando o estigma de que a boa arte deve evitar ser explícita e panfletária. O seu trabalho é assumidamente um trabalho contra o ur-fascismo, uma forma de luta pela criação:

Fico triste com essa aproximação escabrosa do mundo real com meu trabalho. Já fui muito pra rua, até que em determinado ponto tive o braço quebrado pela polícia e entendi que eu poderia fazer muito mais da prancheta quando pudesse voltar a desenhar. [...] entendi que a minha forma de atuação no cenário que se aproximava seria através da arte permeada de conteúdo político, que mostra de forma "prática" os perigos de cedermos a determinados interesses na esfera política. (SCHARGEL; UCHOA, 2020, p. 4).

\section{Considerações finais}

Gestado pelo medo, é compreensível o retorno do ur-fascismo com suas novas roupagens contemporâneas. Diferente do autoritarismo, que impõe o seu poder de cima para baixo, o melancólico medo é, inclusive, o que faz o ur-fascismo se alastrar por todas as camadas sociais: entre aqueles que têm muito a perder, mas também entre os que não têm nada (ALBRIGHT, 2018, p. 17). O ur-fascismo surge do sentimento mesquinho e humano de tentar apegar-se a algo quando o mundo nos frustra, daí ser tão disseminado durante e após épocas de crises. Cresce novamente ao redor do mundo com a crise de 2008, que intensificou a recessão democrática global, absorvendo o ressentimento e o rancor e traduzindo-os em políticas antidemocráticas (BRAY, 2019, p. 15).

Para retornar à utopia regressiva, o ur-fascismo emprega quaisquer meios que julgar necessário. Mais do que apenas melancólico, é um movimento essencialmente maniqueísta. $\mathrm{O}$ mundo, para o ur-fascismo, é simplificado entre os "bons" e os "maus", sendo os "bons" aqueles que pertencem à seita do poder hegemônico e os "maus" qualquer um que 
se oponha a ele. Esses termos podem ser substituídos por outros, sem prejuízo de valor. Em geral, qualquer ideologia oposta - e sendo o urfascismo um alveário de contradições, conforme definiu Umberto Eco (2018, p. 32), qualquer ideologia política democrática é oposta a ele, até mesmo o conservadorismo democrático - é tomada como "mau”, mas com particular apreço àqueles que o fascismo considere como comunista, socialista, ou simplesmente progressista. $O$ comunista não precisa ser de fato um comunista, basta que seja um simples democrata para que essa metodologia de poder o classifique como tal, se assim for conveniente.

Isso se deve em parte porque, e aqui há outro pilar de qualquer ur-fascismo, esse movimento precisa de um inimigo. É evidente que a necessidade de inimigos é insuficiente para diferenciar ur-fascismo de autoritarismo, ambos lidam com oposições binárias e maniqueístas. Em um resumo simples que permite compreender de forma geral a diferença da questão do inimigo no autoritarismo, no ur-fascismo e no totalitarismo: no autoritarismo, os inimigos são perseguidos, porque se opõem politicamente ao regime; no ur-fascismo os inimigos são perseguidos, porque são grupos aleatórios desumanizados e, no totalitarismo, todos são inimigos. Em suma, o ur-fascismo só existe se houver um inimigo a ser combatido e, na ausência de um inimigo real, é necessário exercitar a imaginação e criálo. Mais ainda: o inimigo precisa sofrer um processo de desumanização. $\mathrm{O}$ inimigo não é humano, é um monstro. A ele recai toda a maldade do mundo.

Qualquer ur-fascismo se coloca contra o inimigo monstruoso. Ao passo que o pilar de uma democracia liberal é um sistema de tolerância mútua entre adversários políticos, o dissenso é intolerável ao ur-fascismo (ECO, 2018, p. 49). O que explica esse movimento ser antidemocrático em sua essência: na metodologia ur-fascista não há espaço para divergência, para o diferente. $\mathrm{O}$ diferente é o monstro, o desumano. $\mathrm{O}$ monstro pode ser de uma cultura ou etnia diferente, ou, mais conveniente, de uma ideologia 
política oposta, ou mesmo tudo isso amalgamado. O monstro pode ser o judeu, o comunista, o muçulmano, o etíope, o cigano, o homossexual, não importa. A escolha é arbitrária e varia de nação para nação, conforme as características culturais que o ur-fascismo absorve em cada localidade. Importa apenas que algum grupo específico seja desumanizado e perseguido.

Tanto a obra de Kucinski quanto a de Dênis Mello absorvem fragmentos do ur-fascismo brasileiro e, pela hipérbole distópica, recriam versões totalitárias desse ur-fascismo. Embora possuam dissensos notáveis, em particular em respeito à construção e foco narrativo - A nova ordem se dispõe a explorar com mais atenção a cúpula do poder, enquanto Teocrasília se detém sobre a resistência armada -, ambos trazem aspectos essenciais do ur-fascismo: a desumanização do inimigo objetivo, o reacionarismo, o belicismo, entre outros. Dada a religiosidade do país e o crescimento das religiões neopentecostais, é natural que ambas tratem de teocracias, como o próprio título do livro de Mello já indica, pois, como apontou Paxton (2007, p. 72-73), o ur-fascismo absorve idiossincrasias do tempo e local em que aparece, motivo pelo qual jamais poderá ser compreendido como um fenômeno hermético.

\section{Referências}

ADORNO, Theodor et al. The authoritarian personality. New York: Science Editions, 1964.

ALBRIGHT, Madaleine. Fascismo: um alerta. Tradução de Jaime Biaggio. São Paulo: Planeta, 2018.

ANTISSEMITISMO cresce na Europa. Deutsch Welle Brasil, Bonn, 15 fev. 2019. Disponível em: https://p.dw.com/p/3DRO5. Acesso em: 15 jul. 2021. 
APÓS ‘DESPETIZAÇÃO’ de Onyx na Casa Civil, faltaram funcionários para demitir e contratar. O Dia, Rio de Janeiro, 10 jan. 2019. Disponível em: https://odia.ig.com.br/brasil/2019/01/5610221-apos-despetizacao-de-onyx-na-casa-civil-faltaram-funcionarios-para-demitir-e-contratar.html. Acesso em: 27 nov. 2020.

ARENDT, Hannah. As origens do totalitarismo: totalitarismo, o paroxismo do poder. Rio de Janeiro: Editora Documentário, 1978.

BOGHOSSIAN, Bruno. Na cultura, governo asfixia críticos e monta máquina de propaganda. São Paulo, Folha de S.Paulo, 06 out. 2019. Disponível em: https://www1.folha.uol.com.br/colunas/bruno-boghossian/2019/10/ na-cultura-governo-asfixia-criticos-e-monta-maquina-de-propaganda. shtml. Acesso em: 09 dez. 2020.

BRAY, Mark. Antifa: o manual antifascista. Tradução de Guilherme Ziggy. São Paulo: Autonomia Literária, 2018.

BUARQUE, Chico. Essa gente. São Paulo: Companhia das Letras, 2019.

BURGESS, Anthony. Laranja mecânica. Tradução de Fábio Fernandes. São Paulo: Aleph, 2019.

CAMPBELL, Joseph. O herói de mil faces. Tradução de Adail Sobral. São Paulo: Cultrix/Pensamento, 2013.

ECO, Umberto. O fascismo eterno. Trad. Eliana Aguiar. Rio de Janeiro: Record, 2018.

FELICE, Renzo de. Explicar o fascismo. Edições 70: Lisboa, 1976.

FOUCAULT, Michel. Microfísica do poder. Trad. Roberto Machado. Rio de Janeiro: Edições Graal, 1979.

GALLEGO, Esther Solano. O ódio como política: a reinvenção das direitas 
no Brasil. São Paulo: Boitempo, 2018.

GLOBAL democracy has another bad year. The Economist, London, 22 jan. 2020. Disponível em: https://www.economist.com/graphic-detail/2020/01/22/global-democracy-has-another-bad-year. Acesso em: 04 out. 2020 .

HUXLEY, Aldous. Admirável mundo novo. Tradução de Vidal de Oliveira. São Paulo: Globo, 2010.

HUXLEY, Aldous. Regresso ao admirável mundo novo. Rio de Janeiro: Editora Itatiaia, 2000.

KUCINSKI, Bernardo. A nova ordem. São Paulo: Alameda, 2019.

. K.: relato de uma busca. São Paulo: Companhia das Letras, 2016.

. Os visitantes. São Paulo: Companhia das Letras, 2016.

LEPORE, Jill. A golden age for dystopian fiction. The New Yorker, New York, 29 may 2017. Disponível em: https://www.newyorker.com/magazine/2017/06/05/a-golden-age-for-dystopian-fiction. Acesso em: $09 \mathrm{dez}$. 2019.

MATOS, Thais. '1984’ e 'A revolução dos bichos': por que George Orwell é o único clássico na lista de mais vendidos de ficção no Brasil? G1, Rio de Janeiro, 20 maio 2019. Disponível em: https://g1 .globo.com/pop-arte/noticia/2019/05/20/1984-e-a-revolucao-dos-bichos-por-que-george-orwell-e-o-unico-classico-na-lista-de-mais-vendidos-de-ficcao-no-brasil.ghtml. Acesso em: 30 jun. 2019.

MELLO, Dênis. Teocrasília. Rio de Janeiro: CJT Comunicação e Tecnologia, 2018.

MOUNK, Yascha. El pueblo contra la democracia: por qué nuestra libertad 
está en peligro y cómo salvarla. Tradução de Albino Mosqueira. EspasaLibros: Barcelona, 2018.

NEW REPORT: Freedom in the world 2020 finds established democracies are in decline. Freedom House, Washington, 04 mar. 2020. Disponível em: https://freedomhouse.org/article/new-report-freedom-world-2020-finds-established-democracies-are-decline. Acesso em: 06 jul. 2020.

ORWELL, George. 1984. Tradução de Alexandre Hubner e Heloisa Jahn. São Paulo: Companhia das Letras, 2009.

PACHUKANIS, Evgeni B. Fscismo. Tradução de Paula de Almeida. São Paulo: Boitempo, 2020.

PAXTON, Robert. A anatomia do fascismo. Tradução de Patrícia Zimbres e Paula Zimbres. São Paulo: Paz e Terra, 2007.

RUNCIMAN, David. Como a democracia chega ao fim. Tradução de Sérgio Flaksman. São Paulo: Todavia, 2018.

SCHARGEL, Sergio. "Fascism is once more at our doors, and we still refuse to see and treat it by its name": an interview with Cultural Philosopher Rob Riemen. Revista Cantareira, [S.I.], n. 33, p. 97-107, jul./dez. 2020. Disponível em: https://periodicos.uff.br/cantareira/article/view/40711. Acesso em: 14 jan. 2021.

SCHARGEL, Sergio; UCHOA, Camila W. Teocrasília: distopia de um Brasil possível. Revista Escrita, Rio de Janeiro, n. 27, p. 1-8, 2020. Disponível em: https://www.maxwell.vrac.puc-rio.br/49685/49685.PDF. Acesso em: 31 mai. 2021. DOI:10.17771/PUCRio.escrita.49685.

STANLEY, Jason. Como funciona o fascismo: a política do "nós" e "eles". Tradução de Bruno Alexander.Porto Alegre: L\&PM, 2018. 
SUNSTEIN, Cass R. (org.). Can it happen here? Authoritarianism in America. HarperCollins: New York, 2018.

TRINDADE, Naira. Osmar Terra: 'Para dirigir a Ancine tem que entender de cinema, sendo evangélico ou não' O Globo, Rio de Janeiro, 03 set. 2019. Disponível em: https://oglobo.globo.com/cultura/osmar-terra-para-dirigir-ancine-tem-que-entender-de-cinema-sendo-evangelico-ou-nao-23925074. Acesso em 21 nov. 2021.

VEJA quais deputados e senadores fazem parte da bancada evangélica. Brasília, Congresso em foco, 15 set. 2020. Disponível em: https://congressoemfoco.uol.com.br/legislativo/veja-quais-deputados-e-senadores-fazem-parte-da-bancada-evangelica/. Acesso em: 17 mar. 2021.

VIANNA, Luiz Fernando. As besteiras do Brasil estão de volta. Folha de S.Paulo, São Paulo, 21 out. 2006. Crítica/crônicas. Disponível em: https:// www1.folha.uol.com.br/fsp/ilustrad/fq2110200622.htm. Acesso em: 27 nov. 2020.

ZAMIÁTIN, Ievguêni. Nós. Tradução de Gabriela Soares. São Paulo: Aleph, 2017.

Portraits of brazilian fascisms: relationship between Teocrasília and a nova ordem with bolsonarism

Abstract: Dystopia is one of the most political forms that literature can assume, since it absorbs traces of the politics of real to distort it in a nightmare. In this scope, it is symptomatic that novels such as Teocrasilia, published in 2018, and A nova ordem, in 2019, are launched during the rise of an "ur-fascist" movement in Brazil, to use the concept created by Umberto Eco. Both absorb fragments of bolsonarism and, in the process of falsifying the real, create a literary reality in which a Brazilian version of ur-fascism became totalitarian. This work will put the political theory about ur-fascism into dialogue with the two objects, in order to understand how traces of this political movement are apprehended by fiction. In this way, it will contribute 
to the state of the art by making it possible to understand ur-fascism in several of its potentialities, as well as the ways in which political literature recreates political theory.

Keywords: Political theory. Dystopia. Ur-fascism.

Recebido em: 01/06/2021

Aceito em: 20/09/2021 